\title{
28 Research Soure \\ Urban Poverty and Child Malnutrition in India: A Geographical Analysis
}

\section{UJJWAL Das ( $\nabla$ ujjwaldas608@gmail.com )}

International Institute for Population Sciences https://orcid.org/0000-0002-3791-4805

\section{Sanjay K. Mohanty}

International Institute for Population Sciences

\section{Research article}

Keywords: industrialization, rich-poor ratio, concentration index, malnourished.

Posted Date: October 21st, 2021

DOl: https://doi.org/10.21203/rs.3.rs-965164/v1

License: (c) (i) This work is licensed under a Creative Commons Attribution 4.0 International License. Read Full License 


\section{Abstract}

\section{Background}

The rapid pace of industrialization, the unprecedented growth of migration from rural to urban area for a better opportunity and unequal distribution of wealth explain paradox situation of the country, still, a significant proportion of the world's poor live in India, as do a significant proportion of the world's malnourished children. This paper examines the variation of child malnutrition in urban areas of India segregated by the poor and non-poor population over the two time periods 2005-06 and 2015-16. Crosssectional data from the third and fourth round of the National Family Health Survey conducted during 2005-06 and 2015-16 have been used for the analysis.

\section{Methods}

Focusing on urban health and regional development we have used poor-non poor ratio, concentration index, and binary logistic regression among the selected child health variables namely stunting, underweight, fever and diarrhea in India.

\section{Results}

The findings indicate that young children, especially those under the age of five, from economically poor states like Bihar, Odisha and Madhya Pradesh are more vulnerable to higher levels of undernutrition and morbidity in urban areas, due in part to poor residential, poor health care services, poor health of mothers, and poor educational status of their parents in the community.

\section{Conclusion}

Based on the findings the study suggests that improving the public services such as basic health care and the education level of the mothers among urban poor can ameliorate the negative impact of poverty on childhood undernutrition.

\section{Introduction}

The rapid pace of industrialization, urbanization and market globalization has a major issue and challenges in the urban area and has a significant impact on epidemiological and nutritional transition. This relevance context is particularly common in developing countries like India. United Nations population projection suggested that the urban population was 3 billion in 2005, now it has continuously increased and is expected by 2030 nearly two-third of the global population in urban areas. At the same time, the population living in urban areas was only 2 percent in 1850, 6 percent in 1900 and 16 percent by 1950. It has further increased to 2.9 billion to 3.4 billion (18 percent to 50 percent) and is expected to cross 60 percent according to 6.3 billion in 2050 (UN, World Urbanization Prospect, 2005). The explosive growth of the urban population in developing countries is largely due to the migration of unskilled workers from rural areas to urban areas. This has been caused by greater inequalities in income and poverty within urban areas (Abhishek and Mohanty, 2011). The emerging phenomenon of urbanization has proportionately 
brought about health inequalities between different socio-economic groups within regions and between regions (Arokiasamy et al., 2013). Where despite under-nutrition, obesity and other diseases prevalence have become a growing public health challenge. It has been observed that urban populations exhibit more variation in poverty, morbidity, mortality, and nutritional status compared to rural populations (Basta, 1977; Bradley et al., 1992). Previous studies found that poverty level malnutrition is significantly higher in poor countries than in better-off countries. The recent estimate showed that 36 percent of children are malnourished in low-income counties where 12 percent in middle-income countries and 1 percent in developed countries, respectively (World Bank, 2000).

The situation of India has the world's second-largest urban population, next to china and it has faced an unprecedented scale of urbanization. Over 30 percent of the Indian population living in urban areas and the proportion is projected to grow to 40 percent, or about 590 million people, by 2030 . Thus unprecedented growth of the urban population results from increasing urban poverty in India. According to the Rangarajan committee estimated urban poverty report in India (2009), 26 percent of the urban population lives below the poverty line. The ratio of urban poverty in some poor states is higher than in rural poverty. The spatial distribution of poverty in India has emerged as a matter of urgent challenging issues of wide regional variations within states. Subsequently, the huge disparity in rural and area areas increased the inequalities between communities. On the other hand, the high slum population in a hazardous location in the urban areas has increased the risk of morbidity and mortality in children below 5 years of age group. In slum areas despite food production, disease control and economic and social development all are lead to the acute facing of child malnutrition. According to National Family Health Survey-IV (2015-16) report, 32 percent of children below five years of age are underweight, 38 percent are stunted and 19 percent are wasted respectively. This indicates that under-nutrition is a major problem in every part of India but it is most prevalent in states of Bihar, Uttar Pradesh, Madhya Pradesh and Rajasthan, where more than half of the children were underweight and stunted (Pathak and sing, 2009).

Poverty along with the rising cost of health care services is the leading cause of inequality in health and health care utilization within urban areas. The health care facility in India mostly focused on different health indicators of different socioeconomic groups by slum and non-slum population. The living and health conditions are different from the poor to non-poor population in urban India. The residing slum population has more vulnerable due to contact infection, falls sick and suffer prolonged illness. Moreover, women and children are facing more problems in bad recommended health. Approximately $80 \%$ of the maternal deaths occur due to hemorrhage, sepsis, unsafe induced abortion, hypertensive disorder of pregnancy, and obstructed labor (Adam et al., 2005). Considering the issue study examines the variation of child health (stunting, underweight, fever, diarrhea) status with respect to child malnutrition among the urban poor and non-poor in India during 2005-16.

\subsection{Review of Literature}

Several studies have suggested child health conditions among the urban poor and non-poor across the state level and national level in India (Rajesh et.al 2015; Basu et. al 2014; Chaudhuri, 2009; Murgai 2003). They found poverty has greatly affected their quality of life and children are phasing more problems in 
terms of health and nutritional status in slum areas ((Viteri, 1987; Cleland et al., 1992; Gilbert and Gugler, 1992; Brockerhoff, 1995; Sastry, 1997). Nolan et al, 2007 found young children; especially those under the age of five, from disadvantaged families, are particularly vulnerable to heightened levels of morbidity and mortality in urban areas, due in part to poor residential and environmental conditions as well as household deprivation in a highly commoditized context. Baker and Schuler, 2004 suggested that double burden of diseases such as Dengue fever, tuberculosis and HIV plague are more common in urban residences. Agarwal and Taneja, 2005 argue that Populations living in non-notified slums are even more vulnerable as these settlements are not recognized by authorities and, hence, usually remain outside the purview of health, nutrition, food subsidy, and other civic services. Women in particularly are more vulnerable due to unequal and meager wages, education as compare to men (Loughhead, Mittal, \& Wood, 2001). Indeed, slum-dwelling women in India are more likely to be underweight than their non-slum dwelling counterparts (Gaur et.al.,2013) and poor women are more likely to report worse maternal and child health indicators than their non-poor counterparts (Prakash and Kumar. 2013). Rajesh Kumar Rai. 2015 proposed the obesity is closely associated with chronic health problems such as diabetes, hypertension, cardiovascular disease, cancer among the urban population because of the higher standard of living, availability of processed and fast foods, dependence on television for leisure and without physical activity in employed women. Huey SL et al.2019 observed a higher risk of underweight and lower WAZ was associated with shorter maternal height $(<150 \mathrm{~cm})$ and low birth weight.

Apart from the unhygienic and health-threatening surroundings, limited access to healthcare services makes a serious issue to, fall sick and suffer long time diseases (Kumar and Mohanty.2011). The other contributing factors the high cost of health services - which leads to out-of-pocket catastrophic health expenditure and descent into poverty, more so among the most vulnerable groups. Das and Hammer, 2007 found urban residents may be especially vulnerable to the higher cost of health services, which are often of poor quality and associated with unnecessary drug purchases. Fotso J. Chistophe, 2006 suggested the heterogeneity of urban areas higher than the rural area for the harboring pocket of severe poverty and deprivation concentrated of ill health among the poor. Jose Shyma,2013 proposed Large economic inequality widening the gap in utilization of prenatal care and skilled birth attendance over the period thus the poor mothers, large proportions of births were delivered at home without any medical assistance as compared to non-poor mothers in the urban area. Kumar and Singh.2014 indicated financial barrier also plays an important role in increasing inequality in urban India because the poor can reap from the better food supply in urban areas, while the rural poor can benefit from their own food production.

\section{Data And Methods}

\subsection{Data}

The present study uses the data from two rounds of the National Family Health Survey (NFHS) which were conducted during 2005-06 and 2015-16. The NFHS is one of the important large-scale demographic and health surveys in India which provides a sufficient source of information about population, fertility, mortality, family planning, health, health care utilization and nutritional status. The selection of sampling was based on probability proportional size in both urban and rural areas. This study mainly focuses on a 
sample of urban children in India. The NFHS-III (2005-06) collected information from 109,041 households and 124,385 women age 15-49, from 29 states that comprise 99 percent of the Indian population. In addition, the survey collected information on 56,438 children 5 years preceding surveys. With regards to urban population information was collected from 50,236 households, 56,961 women in the same age group and 19,483 children from the same reference period. While NFHS-IV (2015-16) collected information from 601,509 households and 699,686 women aged 15-49, from 36 states and union territories that comprise 99 percent of India's population. In addition, the survey collected information on 259,627 children 5 years preceding surveys. With regards to the urban population, information was collected from 175,946 households, 204,753 women in the same age group and 61,379 children from the same reference periods.

\section{Outcome variables}

The outcome variables in the present study are height for age (stunting), weight for height (underweight), fever and diarrhea. These variables are the standardized measure of child nutrition which is commonly used in prior studies (WHO Multicenter Growth Reference Study Group, 2006). Whereas stunting is the chronic nutritional indicator and underweight is an acute and chronic form of undernourishment. Child illness of fever and diarrhea are common congenital diseases in poor households.

\section{Independent variables}

A set of explanatory variables were used in the analysis such as household poverty, sex of the child, Birth order, Preceding birth Interval, Age of mother, Education of mother, Religion, Caste, Antenatal care, Delivery care and Exposure to mass media (newspaper, television, radio).

\subsection{Methods}

\section{Identification of urban poor}

The urban poor is defined as the poor living in urban areas - cities, towns and transitory urban areas. It is not only referred to the dimensions of income and food security, but also the availability of basic services, shelter and livelihoods. According to World Bank, Urban poverty is a multidimensional phenomenon, and the poor suffer from various deprivations e.g. lack of access to employment, adequate housing and services, social protection and lack of access to health, education and personal security. The Urban Basic Services for Poor (UBSP) and Integrated Housing \& Slum Development Programme (IHSDP) under Jawaharlal Nehru National Urban Renewal Mission (JNNURM) identified seven basic criteria for the urban poor, especially slum dwellers in cities- (i) Security of tenure (ii) Improved housing (iii) Water supply (iv) Sanitation (v) Education (vi) Health, and (vii) Social security.

The NFHS does not provide direct information on the income or consumption of households. However, NFHS collects the information related to ownership of assets, consumer durable variables, and infrastructure (sanitation facility and source of water), which are can be used as proxy indicators of the household's wealth quintile. To tackle this issue, the cut-off point to identify the urban poor is equated with the officially accepted estimates of consumption data by the planning commission, Government of India. 
For example, in 2004-05 planning commission of India estimated 27 percent urban population were living below the poverty line. Similarly in 2011-12, the Rangarajan committee estimated that about 26 percent of urban people were residing below the poverty line as compared to 31 percent in rural areas. After that, the separate wealth index has constructed for urban and rural areas. Finally, percentile distribution was obtained demarcates the poor and non-poor in urban India and selected states. The selection of states is based on a sufficient sample size. Those states having a sample size of less than 100 have not been used for the analysis whereas seven north-eastern states except Asam have been grouped into one state. A total of 23 states have been used to examine the variation of child health status among urban poor.

Descriptive statistics have been used to understand the differences in child health indicators among the urban poor and non-poor in India. Rich-poor ratio and concentration index have been used for the inequality measurement in two different periods of 2005-06 and 2015-16. The concentration index has varied between +1 to -1 . The negative values indicate that child health indicators are concentrated among the disadvantaged group, while the positive value indicates that health indicators are concentrated among the advantaged group. The closer value is to 1 , the more unequal the health status and close to 0 indicates health status is more equal.

Furthermore, the binary logistic regression is used for the significant effect of child health indicators (stunting, underweight, fever and diarrhea) among the poor and non-poor in urban India. The Arc-GIS software has been used to analyze geographical map distribution among the urban poor in India in two round survey. All work has been done by the statistical software package in STATA version 8.1

\section{Results}

Figure 1 provides a clear picture of urban poor in two different periods in 2005-06 and 2015-16. It was found total 25 and 26 percent of the urban population are living below the poverty line in 2005-06 and 2015-16 respectively. In 2005-06, the northern and western parts of India were 21 percent and 24 percent of the urban population living below the poverty line. But in 2015-16 it was significantly decreased from 19 percent for northern India and 18 percent for the western part of India respectively. The reverse picture was found in the eastern and north-eastern parts of urban India. In 2005-06 urban poverty in eastern and northeastern India was 30 and 22 percent which was increased 35 percent in 2015-16 for both eastern and northeastern India respectively. Among the north-eastern states, the highest level of poverty was increased in Manipur, followed by Assam and Nagaland. Among the 29 states of India, only 10 states urban poverty was declined from 2005-06 to 2015-16. The highest decline was in Sikkim. In other 17 states, urban poverty still increased from 2005-06 to 2015-16. The highest increased Manipur followed by the Assam, Andhra Pradesh, Bihar, Uttar-Pradesh and West Bengal. And remaining 2 states' poverty was level stagnant in two time periods. These states are

Table 1 shows the state-wise variation of child malnutrition in urban India. It was found that the malnutrition (stunting, underweight, fever and diarrhea) of the urban child has declined from 2005-2016. For instance, stunting, underweight, fever have declined from $54 \%, 48 \%$, and $15 \%$ in $2005-06$ to $43 \%, 40 \%$, and $14 \%$ in 2015-16 among the urban poor children. The highest percentage of stunting and underweight 
both were found in the state of Bihar, Uttar Pradesh, Madhya Pradesh and Rajasthan (Fig. 2). The similar result was also found for child illness of fever and diarrhea. The highest percentage of child illness for both fever and diarrhea was found in the state of Uttrakhand, followed by Uttar Pradesh (Fig. 3). In southern states, Kerala and Telangana illness of fever have relatively higher than the national level. The prevalence of diarrhea among the urban poor children in India was increased from 2005-06 to 2015-16. The highest level increased in Chhattisgarh followed by Uttarakhand and West Bengal.

Table 1 state-wise variation of child malnutrition in urban poor India 2005-16 


\begin{tabular}{|c|c|c|c|c|c|c|c|c|c|}
\hline \multicolumn{2}{|l|}{ SI } & \multicolumn{2}{|c|}{ Stunting } & \multicolumn{2}{|c|}{ Underweight } & \multicolumn{2}{|l|}{ Fever } & \multicolumn{2}{|c|}{ Diarrhea } \\
\hline No. & States & $\begin{array}{l}2005- \\
06\end{array}$ & $\begin{array}{l}2015- \\
16\end{array}$ & $\begin{array}{l}2005- \\
06\end{array}$ & $\begin{array}{l}2015- \\
16\end{array}$ & $\begin{array}{l}2005- \\
06\end{array}$ & $\begin{array}{l}2015- \\
16\end{array}$ & $\begin{array}{l}2005- \\
06\end{array}$ & $\begin{array}{l}2015- \\
16\end{array}$ \\
\hline 1 & Andhra Pradesh & 49.0 & 47.0 & 40.4 & 46.0 & 5.6 & 5.2 & 5.6 & 5.4 \\
\hline 2 & Assam & 54.9 & 31.9 & 43.7 & 31.1 & 22.9 & 15.0 & 6.0 & 3.2 \\
\hline 3 & Bihar & 56.0 & 48.2 & 55.8 & 43.6 & 20.4 & 12.6 & 12.7 & 9.7 \\
\hline 4 & Chhattisgarh & 49.1 & 38.3 & 47.3 & 39.4 & 8.9 & 12.7 & 6.5 & 11.2 \\
\hline 5 & Delhi & 58.7 & 40.8 & 47.5 & 31.2 & 9.1 & 11.6 & 9.1 & 9.2 \\
\hline 6 & Goa & 37.9 & NC & 36.8 & NC & 19.7 & NC & 6.8 & NC \\
\hline 7 & Gujarat & 60.3 & 45.9 & 50.0 & 44.2 & 17.3 & 9.3 & 12.2 & 9.1 \\
\hline 8 & Haryana & NC & 44.7 & NC & 36.5 & NC & 13.6 & NC & 9.7 \\
\hline 9 & $\begin{array}{l}\text { Jammu \& } \\
\text { Kashmir }\end{array}$ & NC & 29.7 & NC & 19.5 & NC & 12.3 & NC & 5.1 \\
\hline 10 & Jharkhand & 51.2 & 46.3 & 57.0 & 51.6 & 23.0 & 13.4 & 17.0 & 7.3 \\
\hline 11 & Karnataka & 50.4 & 44.2 & 42.9 & 40.0 & 11.9 & 7.2 & 6.9 & 3.8 \\
\hline 12 & Kerala & NC & 22.4 & NC & 28.0 & NC & 17.7 & NC & 5.5 \\
\hline 13 & $\begin{array}{l}\text { Madhya } \\
\text { Pradesh }\end{array}$ & 55.1 & 45.6 & 64.8 & 44.4 & 14.9 & 10.6 & 14.7 & 10.5 \\
\hline 14 & Maharashtra & 56.1 & 35.0 & 45.3 & 42.1 & 7.7 & 12.3 & 4.5 & 4.2 \\
\hline 15 & Orissa & 50.3 & 36.4 & 46.9 & 39.3 & 15.7 & 12.3 & 11.0 & 9.8 \\
\hline 16 & Punjab & NC & 41.9 & NC & 31.4 & NC & 19.1 & NC & 7.9 \\
\hline 17 & Rajasthan & 45.0 & 43.9 & 35.1 & 41.0 & 17.3 & 12.2 & 17.9 & 8.6 \\
\hline 18 & Tamil Nadu & 40.8 & 35.2 & 42.6 & 30.9 & 8.3 & 7.9 & 4.5 & 7.8 \\
\hline 19 & Telangana & NA & 33.8 & NA & 41.2 & NA & 17.5 & NA & 12.0 \\
\hline 20 & Uttar Pradesh & 63.5 & 46.6 & 49.1 & 39.9 & 18.1 & 20.4 & 9.5 & 15.4 \\
\hline 21 & Uttarakhand & NC & 47.8 & NC & 34.4 & NC & 29.0 & NC & 17.5 \\
\hline 22 & West Bengal & 50.4 & 40.5 & 42.9 & 40.6 & 26.2 & 13.7 & 2.3 & 6.3 \\
\hline 23 & $\begin{array}{l}\text { North-Eastern } \\
\text { states }\end{array}$ & 48.92 & 31.26 & 35.2 & 20.7 & 21.3 & 11.4 & 12.3 & 6.1 \\
\hline & Urban India & 54.45 & 42.49 & 47.9 & 39.9 & 14.9 & 13.6 & 9.1 & 9.5 \\
\hline
\end{tabular}

Note: NC- Not Calculated sample size below 100 and NA- Not Available in that periods 
In table 2 showed the poor non-poor ratio has almost the same or decreased in the two rounds of the survey from NFHS-III to NFHS-IV for all the states except Andhra Pradesh. Overall India's result shows decreased the rich-poor in underweight from 1.9 to 1.7 from NFHS-III to NFHS-IV. The result of the concentration index indicates that economic inequality for both stunting and underweight have increased from -0.04 to -0.05 and -0.06 to -0.07 in 2005-16. It is also confirmed that children from pro-poor economic states (Bihar, Chhattisgarh, Orissa, and Madhya Pradesh) share the higher burden of sub-optimal growth due to undernourishment. The result of stunting shows the varying degree of economic inequality across the states in urban India.

Table 2 Poor-Non poor ratio and concentration index with respect to child malnutrition (Height-for-age $<-2$ S.D. and weight-for-age <-2 S.D.) across the states, Urban India, 2005-2016. 
Poor-Non poor Ratio

SI

No. States

$1 \quad$ Andhra Pradesh $\quad 1.5$

2 Assam

3 Bihar

4 Chhattisgarh

5 Delhi

6 Goa

7 Gujarat

8 Haryana

9 Jammu \& Kashmir

10 Jharkhand

11 Karnataka

12 Kerala

13 Madhya

Pradesh

14 Maharashtra

15 Orissa

16 Punjab

17 Rajasthan

18 Tamil Nadu

19 Telangana

20 Uttar Pradesh

$21 \quad$ Uttarakhand

22 West Bengal

23 North-eastern states

Urban India

$06 \quad 16$
Stunting

2005- 2015- 2005- 2015-

1.9

1.7

2.1

2.3

1.7

1.5

1.5

1.9

2.0

2.7

1.4

NC

NC

1.4

NC

1.9

1.7

1.8

1.6

1.6

1.1

NC

1.5

1.6

1.3

1.8

1.5

1.8

2.9

2.4

1.8 NC

1.6

1.2

1.6

2.0

1.6

NA

2.2

2.0

1.5

NC

1.7

2.6

2.3

1.8

1.6

1.7

1.7

1.9

1.9

$\begin{array}{ll}1.7 & 1.8\end{array}$

1.7
Concentration Index

Stunting

Underweight

2005- 2015- 2005- 2015-

$\begin{array}{llll}06 & 16 & 06 & 16\end{array}$

$\begin{array}{llll}-0.14 & -0.01 & -0.05 & 0.01\end{array}$

$\begin{array}{llll}0.11 & -0.06 & -0.03 & -0.05\end{array}$

$\begin{array}{ll}-0.03 & -0.09\end{array}$

$-0.04 \quad-0.08$

$-0.10$

0.11

$-0.03$

$-0.04$

$-0.02$

$-0.22$

0.01

$-0.22$

$0.00 \quad N C$

$-0.15 \quad N C$

$-0.12 \quad 0.00$

$-0.15$

0.00

NC

$-0.12$

NC

$-0.04$

NC

$-0.09$

NC

$-0.27$

0.00

$-0.04$

0.00

$-0.07$

$-0.11$

$-0.06$

$-0.25$

$-0.01$

NC

$0.13 \quad \mathrm{NC}$

0.00

0.00

$-0.05$

$-0.03$

$-0.05$

$-0.11 \quad 0.00$

$-0.05 \quad-0.03$

$-0.08$

$-0.10$

$-0.05$

$-0.06$

0.03

0.00

$-0.04$

$-0.09$

$-0.13$

$-0.07$

$-0.01$

$-0.09$

$\begin{array}{ll}-0.14 & -0.03\end{array}$

$-0.16$

$-0.01$

NA

NA

$-0.12$

0.01

0.01

$-0.09$

0.02

$-0.09$

NC

$-0.05$

NC

$-0.05$

$-0.10$

$-0.06$

$-0.10$

$-0.12$

0.01

$-0.08$

$-0.07$

$-0.11$ 
Note: NC- Not Calculated sample size below 100 and NA- Not Available in that periods

The proportion of the nutritional status of children varied socio-economic background characteristics among the urban poor was presented in Table 3. The result indicates that child malnutrition ware lower in first birth order, higher preceding birth interval, educated mother, children belonging to SC/ST caste group and Hindu religious community. Similar results were also found for antenatal care and mass media. Those mothers have received at least four antenatal cares during the pregnancy, malnutrition level relatively lower than the less than four antenatal cares. Similarly, those mothers have been exposed to mass media child illness of diarrhea and fever relatively lower than not exposed to mass media mother.

Table 3 socio-economic differences in child malnutrition status in urban poor in India 2005-16 
Stunting

Background

Characteristics

\section{Birth order}

1

$3+$

\begin{tabular}{llllllll}
48.84 & 38.44 & 42.91 & 34.31 & 16.25 & 13.82 & 10.04 & 9.75 \\
\hline 49.81 & 41.08 & 41.89 & 36.74 & 16.09 & 12.83 & 9.58 & 9.81 \\
\hline 56.12 & 45.01 & 47.46 & 40.13 & 15.39 & 15.17 & 10.24 & 10.46 \\
\hline
\end{tabular}

Preceding birth

interval

$<24$ months

24-47

$>48$

Sex of the child

Male

Female

\section{Mother's age at birth}

$15-24$

25-34

$35+$

\section{Mother's education}

No education

Primary

Secondary

Higher

\section{Caste}

$\mathrm{SC} / \mathrm{ST}$

OBC

other

\section{Religions}

Hindu

Muslim

Underweight

Fever

Diarrhea

$\begin{array}{llllllll}2005- & 2015- & 2005- & 2015- & 2005- & 2015- & 2005- & 2015- \\ 06 & 16 & 06 & 16 & 06 & 16 & 06 & 16\end{array}$

$$
16
$$

$$
06
$$$$
16
$$$$
06
$$$$
\text { 16 }
$$

\begin{tabular}{llllllll|}
\hline 61.63 & 48.71 & 51.16 & 43.43 & 15.23 & 13.83 & 8.6 & 10.4 \\
\hline 53.41 & 43.28 & 44.69 & 38.75 & 15.9 & 13.45 & 11.31 & 10.15 \\
\hline 43.77 & 36.63 & 39.18 & 32.44 & 15.5 & 15.7 & 8.92 & 9.98
\end{tabular}




$\begin{array}{lllllllll}\text { Other } & 50.3 & 33.08 & 36.06 & 22.39 & 14.65 & 10.11 & 12.6 & 6.48\end{array}$

\section{Received Antenatal}

care

\begin{tabular}{lllllllll}
\hline No & 56.56 & 45.47 & 51.38 & 39.82 & 19.03 & 14.81 & 13.79 & 11.48 \\
\hline Yes & 47.47 & 38.25 & 42.1 & 35.23 & 17.66 & 16.45 & 11.48 & 11.92
\end{tabular}

\section{Delivery care}

\begin{tabular}{lllllllll}
\hline Home & 56.67 & 46.33 & 47.54 & 40.91 & 15.75 & 15.24 & 10.05 & 10.54 \\
\hline Public & 48.2 & 40.54 & 41.79 & 36.59 & 15.87 & 12.93 & 10.36 & 9.21 \\
\hline Private & 44.12 & 38.81 & 39.71 & 33.95 & 15.86 & 15.84 & 9.02 & 11.98 \\
\hline
\end{tabular}

Mass media

\begin{tabular}{lllllllll}
\hline No & 55.69 & 47.18 & 47.9 & 41.73 & 15.63 & 14.86 & 10.17 & 11.05 \\
\hline At least one & 50.66 & 39.29 & 42.92 & 35.24 & 15.9 & 13.66 & 9.92 & 9.6
\end{tabular}

Table 4 Differences of child health indicators between slums, non-slums, urban poor, non-poor and rural in India, 2005-16

\begin{tabular}{lllllllllllll} 
& \multicolumn{1}{c}{ NFHS - 2005-06 } & \multicolumn{10}{c}{ NFHS - 2015-16 } \\
\hline Child health & $\begin{array}{l}\text { Urban } \\
\text { slum }\end{array}$ & $\begin{array}{l}\text { Non- } \\
\text { slum }\end{array}$ & $\begin{array}{l}\text { Urban } \\
\text { poor }\end{array}$ & $\begin{array}{l}\text { Non- } \\
\text { poor }\end{array}$ & Rural & $\begin{array}{l}\text { Urban } \\
\text { slum }\end{array}$ & $\begin{array}{l}\text { Non- } \\
\text { slum }\end{array}$ & $\begin{array}{l}\text { Urban } \\
\text { poor }\end{array}$ & $\begin{array}{l}\text { Non- } \\
\text { poor }\end{array}$ & Rural \\
\hline Stunting(<-2SD) & 40.6 & 33.2 & 55.1 & 33.2 & 51.4 & 35.9 & 29.0 & 44.6 & 26.9 & 43.5 \\
\hline $\begin{array}{l}\text { Underweight } \\
\text { (<-2SD) }\end{array}$ & 33.6 & 26.0 & 47.2 & 26.0 & 44.9 & 33.1 & 25.8 & 40.7 & 25.6 & 40.4 \\
\hline $\begin{array}{l}\text { Prevalence of } \\
\text { diarrhea }\end{array}$ & 9.0 & 7.6 & 8.8 & 8.1 & 8.1 & 10.9 & 10.3 & 12.6 & 9.8 & 11.9 \\
\hline $\begin{array}{l}\text { Prevalence of } \\
\text { fever }\end{array}$ & 13.9 & 11.8 & 14.1 & 12.6 & 14.5 & 11.7 & 12.8 & 16.2 & 13.6 & 15.8 \\
& & & & & & & & & & & & \\
\hline
\end{tabular}

Table 4 describes the differences of child health indicators among the urban poor, non-poor, urban slum, and non-slum as well as rural in two rounds of NFHS survey. It was found that the nutritional status of under-five children among the urban poor was relatively higher than the rural, non-slum, and slum residence children at both points of comparison. The difference is remarkable in the prevalence of stunting. The prevalence of stunting among slum children in India was lower (as compared with urban poor) by more than 9 percentage points at both periods. The difference in the prevalence of underweight was more considerable in 2015-16. The prevalence of underweight in urban poor children was relatively higher than the non-poor, slum, and non-slum population. A similar result was also observed for child illnesses of 
diarrhea and fever. The children's belong to the urban poor family have a higher prevalence of diarrhea and fever as compare to the other community. From the above table question raised who are slum dwellers and are they have also the urban poor? NFHS researchers found one definition of slum and urban poverty in 2005-06, that not all poor are slum dwellers and not all slum dwellers are poor (Nolan et al.,2014).

Table 5 Binary logistic model showing the Odd ratio for child undernutrition by different background characteristics in urban India, 2015-16 
Stunting

Background

Characteristics

Non-poor ${ }^{\circledR}$

Poor

$\left[1.343, \quad 1.38^{\star \star \star}\right.$
$1.527]$

$[1.288$,
$1.471]$

$1.12^{\star \star \star}$

[1.038

$1.13^{\star \star \star}$

[1.027

1.244]

\section{Birth order}

$1 \circledR$

$2+$

$1.05^{\star}$

$\left[0.996, \quad 1.07^{\star *}\right.$

[1.009,

$1.13^{\star \star \star}$

$[1.048, \quad 1.03$

[0.940

1.126]

1.145]

1.223]

'1.127]

\section{Preceding birth}

interval

$<24$ months ${ }^{\circledR}$

24-47

$0.83^{\star \star \star}$

$\left[0.770, \quad 0.84^{\star \star \star}\right.$

$[0.779, \quad 1.01$

$[0.924, \quad 1.06$

[0.953

$0.884]$

0.898]

$1.106]$

'1.168]

$>48$

$0.66^{\star \star \star} \quad\left[0.609, \quad 0.65^{\star \star \star}\right.$

0.713]

[0.597,

$0.703]$

$1.12^{\star *}$

$[1.018, \quad 1.04$

[0.921

'1.163]

Sex of the child

Male ${ }^{\circledR}$

Female

$\begin{array}{ll}0.88^{\star * *} & {[0.838,} \\ & 0.934]\end{array}$

$\begin{array}{ll}0.845, & 0.98 \\ 0.946] & \end{array}$

$\begin{array}{ll}{[0.912,} & 1.02 \\ 1.046] & \end{array}$

[0.941

'1.104]

\section{Mother's age at}

birth

15-24®

\begin{tabular}{|c|c|c|c|c|c|c|c|c|}
\hline $25-34$ & $1.09 * *$ & $\begin{array}{l}{[1.010,} \\
1.181]\end{array}$ & $1.09 * *$ & $\begin{array}{l}\text { [1.007, } \\
1.181]\end{array}$ & 0.95 & $\begin{array}{l}{[0.864,} \\
1.053]\end{array}$ & $0.80 * * *$ & $\begin{array}{l}{[0.719} \\
0.891]\end{array}$ \\
\hline $35+$ & $1.13^{*}$ & $\begin{array}{l}{[1.022,} \\
1.269]\end{array}$ & 1.06 & $\begin{array}{l}{[0.943,} \\
1.180]\end{array}$ & $0.77 \star \star \star$ & $\begin{array}{l}{[0.674,} \\
0.889]\end{array}$ & 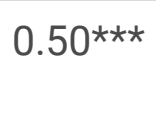 & $\begin{array}{l}{[0.424} \\
0.5921\end{array}$ \\
\hline
\end{tabular}

\section{Mother's}

education

No education ${ }^{\circledR}$

Primary

0.92* [0.836,

0.92* [0.835,

1.07

$[0.950, \quad 0.98$

$[0.858$ 
1.008] 1.010] 1.201] 1.120$]$

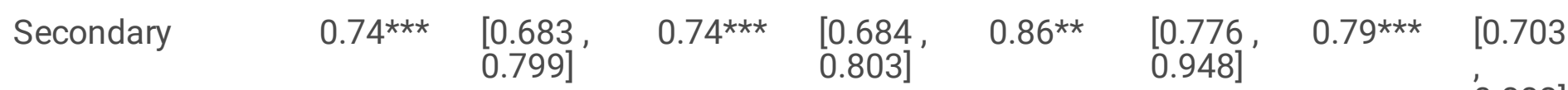
'0.883]

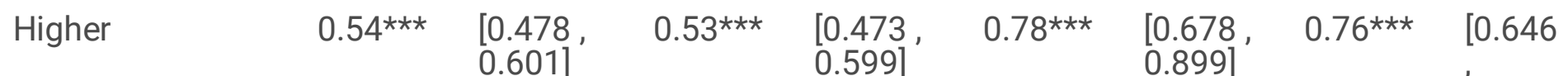
0.601] 0.599] 0.899] 0.896$]$

\section{Caste}

SC/ST ${ }^{\circledR}$

$\mathrm{OBC}$

$0.94 * \quad[0.878$

0.97

$[0.905, \quad 1.07$

1.044]

$[0.978, \quad 1.08$

[0.977

'1.204]

other

\begin{tabular}{|c|c|c|c|c|c|c|}
\hline $0.81^{\star \star \star \star}$ & $\begin{array}{l}{[0.742,} \\
0.874]\end{array}$ & $0.82^{\star \star \star}$ & $\begin{array}{l}{[0.757} \\
0.898]\end{array}$ & 1.04 & $\begin{array}{l}{[0.939,} \\
1.156]\end{array}$ & 1.05 \\
\hline
\end{tabular}

\section{Religions}

Hindu ${ }^{\circledR}$

Muslim

$1.07 * \quad[0.995, \quad 0.96$
$1.143]$

[0.895

$1.34^{\star \star \star}$

[1.233

$1.38^{* \star *}$

[1.256

1.520]

Other

$0.71 * \star \star$

$[0.639$,

$0.45^{\star \star \star}$

$[0.402,1.11 *$

$[0.985$,

$0.76^{\star \star \star} \quad[0.645$

0.885]

\section{Received}

Antenatal care

No ${ }^{\circledR}$

Yes

$0.92 * \quad[0.851$
$1.002]$

0.98

[0.898

$1.063]$

$1.24^{\star \star *}$

$[1.111$

[1.070

'1.374]

\section{Delivery care}

Home ${ }^{\circledR}$

$\begin{array}{lllllllll}\text { Public } & 1.02 & {[0.939,} & 0.97 & {[0.891,} & 0.87 \star \star \star & {[0.784,} & 0.88^{\star \star} & {[0.788} \\ & & 1.100] & & 1.047] & & 0.958] & & 0.991]\end{array}$

Private

0.89 **

$[0.815$,
$0.977]$

$0.84 * \star \star$

$[0.770, \quad 1.03$

$[0.921, \quad 0.94$

[0.823

'1.065]

\section{Mass media}

$\mathrm{No}{ }^{\circledR}$ 
At least one

0.92 *

[0.852,

1.001]

$0.88 * * \star$

[0.812,

$0.957]$

$0.87 * * *$

[0.795,

$0.84^{* \star *}$

[0.750

0.942]

Note: ${ }^{* \star} p<0.01, * \star p<0.05 \& * p<0.10$

Table 5 present the result of binary logistic regression showing the effect of various demographic, socioeconomic and cultural factors in selected child nutritional indicators in urban India. The result suggested that the odds ratio for all nutritional indicators among poor households is relatively higher than the nonpoor households. The odds of stunting and underweight children are 1.05 and 1.07 times in the 2 nd birth order interval in 2015-16 respectively. The odds of having more than 48 months of birth interval child malnutrition relatively lower than the 24-47 months birth interval with 95 percent statistically significant. The indicators of sex, males are reference category, and diarrhea having a female child was higher odds than the other indicators, because the female children's are more susceptible to congenital disease. Similarly, those mothers have higher education odd value significantly decreased from without education. The odd value of having highly educated mothers for stunting and underweight are 0.54 and 0.53 and for child illness of fever and diarrhea are 0.78 and 0.76 with 95 percent with statically significant. The odds of private-sector delivery care are lower value as compare to the public sector among the stunted and underweight poor household children. Similarly, the odds for those women who have exposure to mass media have a lower value for child malnutrition than those who have not been exposed to the mass media in 2015-16 respectively.

\section{Discussion And Conclusion}

The overall purpose of the study was to describe the prevalence of child malnutrition among the urban poor in India during 2005-16. The issue addresses the poor household disparities with selected child health indicators within selected states of urban India. The selection of the state criteria is that first identify the poor with a state-specific cut-off point based on planning commission data, Gov. of India in 2004-05 and 2015-16 respectively. After that, the separate wealth index has constructed for urban areas. Furthermore, the differential in four child health indicators: 1) stunting, 2) underweight, 3) diarrhea, and 4) fever are examined for the country and selected states. The stunting and underweight both are acute and adequate chronic malnutrition over a long time and child illness of diarrhea and fever both are congenital diseases which are more common in urban poor as well as slum dweller.

From the analysis, it was demonstrated that differences in child health indicators in selected states remained substantive over the two time periods. The gaps are more pronounced with respect to being stunting and underweight across the states. The percentage of highest underweight children among poor has found in the state of Jharkhand followed by Andhra Pradesh, Gujarat, Madhya-Pradesh and Bihar, etc. Similarly, the highest level of stunting has found in the state of Bihar followed by Uttrakhand, Andhra Pradesh, and Gujarat. The proportion of child stunting, underweight and fever has decreased among the urban poor in the country during 2005-16, while the differences among the urban poor and non-poor remained stagnant or increased over the period. Whether the children under the age of five higher levels of malnutrition have occurred among urban poor than the non-poor and slum-dwelling counterpart. It 
indicates that reduction the urban poverty in the country simultaneously declined in child malnutrition among the poor, but the distribution of different types of resources and unequal wealth quintile increasing the gap of malnutrition between the urban poor, non-poor as well as rural in the country. Thus urban poor children are more stunted but not more likely to die than their rural counterparts (Nolan et al., 2014).

We also describe the correlates of undernutrition in this context by the different background characteristics of the households. Overall, a higher risk of stunting and underweight and child illness of fever and diarrhea was observed for several correlates including male sex, high birth order, shorter birth interval, and less maternal education. The risk of underweight and child morbidity was associated with below mother age and low birth interval, which was similar among both male and female children (Huey et al., 2019). For considering the maternal factor age, education was highly associated with child malnutrition. Generally, higher maternal education was associated with a lower risk of undernutrition.

In conclusion result of the study has examined child health status and assessed its linkages with the poverty status of households. These findings were obtained from the descriptive analysis. The children of the urban poor in the country are significantly more likely to be underweight, stunted, fever, and diarrhea and less like survive than the urban non-poor. The poor health condition is found in the pro-poor economic backward states such as Bihar, Odisha, Rajasthan and Uttar Pradesh. It has been also found that the prevalence of child illness in some states remains higher in the non-poor group, which implies that poverty may not solely be the determinant of child malnutrition and child illness. Because child health may also depend on the dietary pattern, calorie intake and not merely on the standard of living of households (Bhat et al., 1999). In this context, the study prioritizes the need for the recently drafted National Urban Health Mission (NUHM). A major mandate of NUHM is to improve the health of the urban poor, particularly among slum dwellers and other disadvantaged sections. The NUHM should also address the health issue of the mother, undernutrition of children in high priority states of India for improving the health of the urban poor. In addition to targeting the urban poor, there is a need for a comprehensive nutrition strategy to reduce the burden of undernutrition children all over urban India.

\section{Declarations}

Ethics approval and consent to participate: Not Applicable

Data Availability Statement:

Data used in this study for analysis is publicly available and can be obtained from: http://rchiips.org/NFHS/index.shtml.

Consent for publication: Not Applicable

Competing interests:

The authors declare that they have no Competing interests

Funding:

Page $18 / 24$ 
The authors received no specific funding for this work.

Author Contributions:

Conceptualization, U.D. and S.K.M.; Data curation, UD.; Formal analysis, U.D. and S.K.M.; Funding acquisition, U.D.; Investigation, S.K.M.; Methodology, U.D. and S.K.M. All authors have read and agreed to the published version of the manuscript.

Acknowledgements: Not applicable

\section{References}

1. Agarwal, S., Satyavada, A., Kaushik, S., \& Kumar, R. (2007). Urbanization, urban poverty and health of the urban poor: status, challenges and the way forward. Demography India, 36(1).

2. Agarwal, S. (2011). The state of urban health in India; comparing the poorest quartile to the rest of the urban population in selected states and cities. Environment and Urbanization, 23(1), 13-28.

3. Agarwal, S., \& Taneja, S. (2005). All slums are not equal: Child health conditions among the urban poor. Indian Pediatrics, 42, 233-244.

4. Arif, G. M. (2004) Child Health and Poverty in Pakistan. The Pakistan Development Review 43:3, 211238

5. Arokiasamy, P., Kshipra Jain, Srinivas Goli, and Jalandhar Pradhan. "Health inequalities among urban children in India: A comparative assessment of empowered action group (EAG) and south Indian states." Journal of biosocial science 45, no. 2 (2013): 167-185.

6. Awasthi, S., \& Agarwal, S. (2003). Determinants of childhood mortality and morbidity in urban slums in India. Indian pediatrics, 40(12), 1145-1161.

7. Bapat, U., Alcock, G., More, N. S., Das, S., Joshi, W., \& Osrin, D. (2012). Stillbirths and newborn deaths in slum settlements in Mumbai, India: a prospective verbal autopsy study. BMC pregnancy and childbirth, 12(1), 39.

8. Baker J and Schuler N. 2004. Analyzing Urban Poverty: A summary of methods and approaches. World Bank Policy Research Working Paper 33-99.

9. Brockerhoff M. (1995), "Child survival in big cities: The disadvantages of migrants", Social Science \& Medicine, 40(10), 1371-1383.

10. Basu, D., \& Das, D. (2014). Poverty-hunger divergence in India. Economic and Political Weekly, 49(2),22-24.

11. Bhat, P. M., \& Zavier, F. (1999). Findings of national family health survey: regional analysis. Economic and Political Weekly, 3008-3032.

12. Chauhan, R. K., Mohanty, S. K., Subramanian, S. V., Parida, J. K., \& Padhi, B. (2016). Regional estimates of poverty and inequality in India, 1993-2012. Social Indicators Research, 127(3), 1249-1296.

13. Chaudhuri, S., \& Gupta, N. (2009). Levels of living and poverty patterns: A district-wise analysis for India. Economic and Political Weekly, 44(9), 94-110 
14. Chattopadhyay, A., Roy, T. K., \& Yelamanchili, V. (2005). Are Urban Poor Doing Better than their Rural Counterpart in India? Demo India, 34(2), 299.

15. Cleland J., Bicego J., Fegan G. (1992), “Socioeconomic inequalities in childhood mortality: The 1970s to the 1980s", Health Transition Review, 2, 1-18.

16. Gilbert A., Gugler J. (1992), Cities, poverty and development: Urbanization in the Third World, Oxford University Press, Oxford.

17. Gowda, M. J., Bhojani, U., Devadasan, N., \& Beerenahally, T. S. (2015). The rising burden of chronic conditions among urban poor: a three-year follow-up survey in Bengaluru, India. BMC health services research, 15(1), 330.

18. Gladstone, B. P., Das, A. R., Rehman, A. M., Jaffar, S., Estes, M. K., Muliyil, J., ... \& Bose, A. (2009). Burden of illness in the first 3 years of life in an Indian slum. Journal of tropical pediatrics, 56(4), 221226.

19. Gaur K, Keshri K, Joe W. 2013. Does living in slums or non-slums influence women $₫$ s nutritional status? Evidence from Indian mega-cities. Social Science \& Medicine. 137-146

20. Huey, S. L., Finkelstein, J. L., Venkatramanan, S., Udipi, S. A., Ghugre, P., Thakker, V. M., \& Haas, J. (2019). Prevalence and Covariates of Undernutrition in Young Children Living in Urban Slums of Mumbai, India: A cross sectional study. Frontiers in public health, 7, 191.

21. Joe, W., Mishra, U. S., \& Navaneetham, K. (2008). Health inequality in India: evidence from NFHS 3. Economic and Political Weekly, 41-47.

22. Jose, S. (2013). Economic growth, poverty and malnutrition in India. In EY International Congress on Economics I (EYC2013), October 24-25, 2013, Ankara, Turkey (No. 254). Ekonomik Yaklasim Association.

23. Kakwani, N., Wagstaff, A., \& Van Doorslaer, E. (1978). Socioeconomic inequalities in health: measurement, computation, and statistical inference. Journal of econometrics, 77(1), 87-103.

24. Kumar, A., \& Mohanty, S. K. (2011). State of child health among poor and non-poor in urban India. Genus, 67(1).

25. Kumar, A., \& Mohanty, S. K. (2011). Intra-urban differentials in the utilization of reproductive healthcare in India, 1992-2006. Journal of Urban Health, 88(2), 311-328.

26. Kumar, A., \& Singh, A. (2013). Decomposing the gap in childhood undernutrition between poor and non-poor in urban India, 2005-06. PloS one, 8(5), e64972.

27. Kumar, A., \& Singh, A. (2014). Is economic inequality in infant mortality higher in urban than in rural India?. Maternal and child health journal, 18(9), 2061-2070.

28. Kyu, H. H., Shannon, H. S., Georgiades, K., \& Boyle, M. H. (2013). Association of urban slum residency with infant mortality and child stunting in low and middle income countries. BioMed research international, 2013.

29. Lefebvre, M., Pestieau, P., \& Ponthière, G. (2013). Measuring poverty without the mortality paradox. Social Choice and Welfare, 40(1), 285-316. 
30. Loughhead, S., Mittal, O. \& Wood, G. (2001) Urban poverty and vulnerability in India. DFID's experience from a social policy perspective.

31. Murgai, R., Suryanaryana, M. H., \& Zaidi, S. (2003). Measuring poverty in Karnataka: The regional dimension. Economic and Political Weekly, 38(4), 404-408.

32. Nolan, L., Balasubramanian, P., \& Muralidharan, A. (2014). Urban poverty and health inequality in India. In Population Association of America Annual Meeting. Boston, MA.

33. O'Donnell, O., O'Neill, S., Van Ourti, T., \& Walsh, B. (2016). conindex: Estimation of concentration indices. The Stata journal, 16(1), 112-138.

34. Pathak, P. K., \& Singh, A. (2009). Geographical variation in poverty and child malnutrition in India. Population, poverty and health: analytical approaches, 183-206.

35. Pelletier, D. L. et al., 1995, The effects of malnutrition on child mortality in developing countries. Bulletin of the WHO, 73: 443-448.

36. Paul, B., Saha, I., Mukherjee, A., Biswas, R., Roy, S., \& Chaudhuri, R. N. (2011). Morbidity pattern of lowbirthweight infants in an urban slum of Kolkata, India. The Journal of the Egyptian Public Health Association, 86(3 and 4), 39-43.

37. Pörtner, C. C., \& Su, Y. H. (2018). Differences in child health across rural, urban, and slum areas: Evidence from India. Demography, 55(1), 223-247.

38. Prakash R and Kumar A. 2013.Urban poverty and utilization of maternal and child healthcare services in India. Journal of Biosocial Science. 45:433-449

39. Rai, R. K. (2015). Factors associated with nutritional status among adult women in urban India, 19982006. Asia Pacific Journal of Public Health, 27(2), NP1241-NP1252.

40. Ruzicka, L. T. and Kane, P., 1985, Nutrition and child survival in south Asia. In: K. Srinivasan and S. Mukerji. (eds.), Dynamics of Population and Family Welfare, Bombay: Himalaya Publishing House.

41. Singh, K. D., Alagarajan, M., \& Ladusingh, L. (2015). What explains child malnutrition of indigenous people of Northeast India?. PloS one, 10(6).

42. Saravanan V.S. \& P.P. Mollinga (2011). Environment and human health. An agenda for research. ZEF Working Paper, 82. Bonn: Center for Development Research (ZEF), University of Bonn.

43. Sohrabi, M., \& Tumin, M. (2016). Health issues and challenges among Indian urban poor. Journal of Health Management, 18(3), 460-472.

44. Srivastava, N. M., Awasthi, S., \& Mishra, R. (2008). Neonatal morbidity and care-seeking behavior in urban Lucknow. Indian pediatrics, 45(3).

45. Sastry N. (1997), "What explains rural-urban differentials in child mortality in Brazil?", Social Science \& Medicine, 44(7), 989-1002.

46. United Nations, 2005, World Urbanization Prospects: The 2005 revision. New York :United Nations Population Division.

47. Viteri F.E. (1987), "Nutrition-related health consequences of urbanization”, Food and Nutrition Bulletin, 9(4), 33-59. 
48. WHO MULTICENTRE GROWTH REFERENCE STUDY GROUP (2006). WHO Child Growth Standards: based on length/height-for age, weight-for-age, weight-for-age and body mass index for age-methods and development, World Health Organization, Geneva.

\section{Figures}

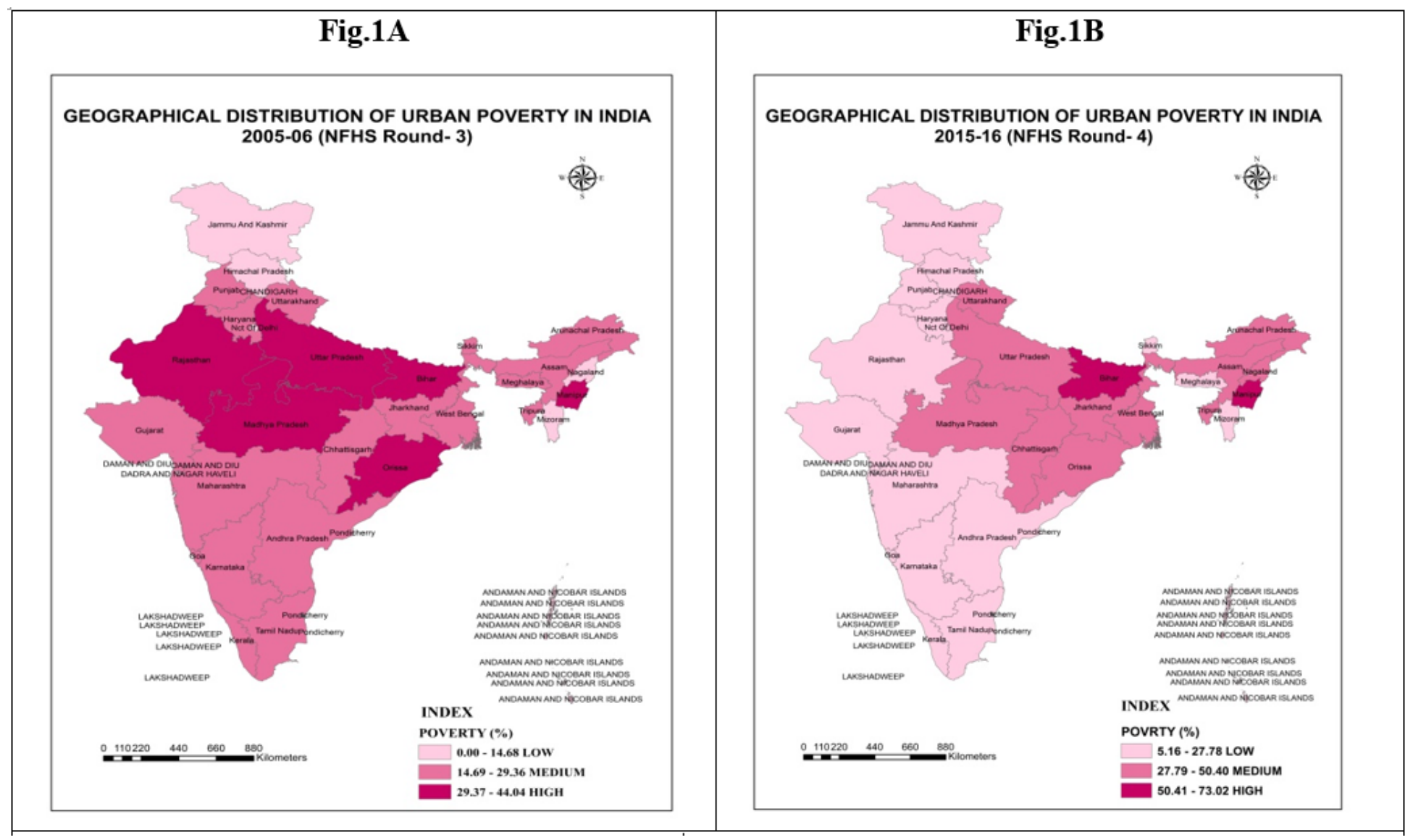

Figure 1

Trends in Percentage of Population Below Urban Poverty Line By States in India, 2005-16 Fig.1A.Percentage of population living below the poverty line in urban India during 2005-06 Fig.1B.Percentage of population living below the poverty line in urban India during 2015-16. 


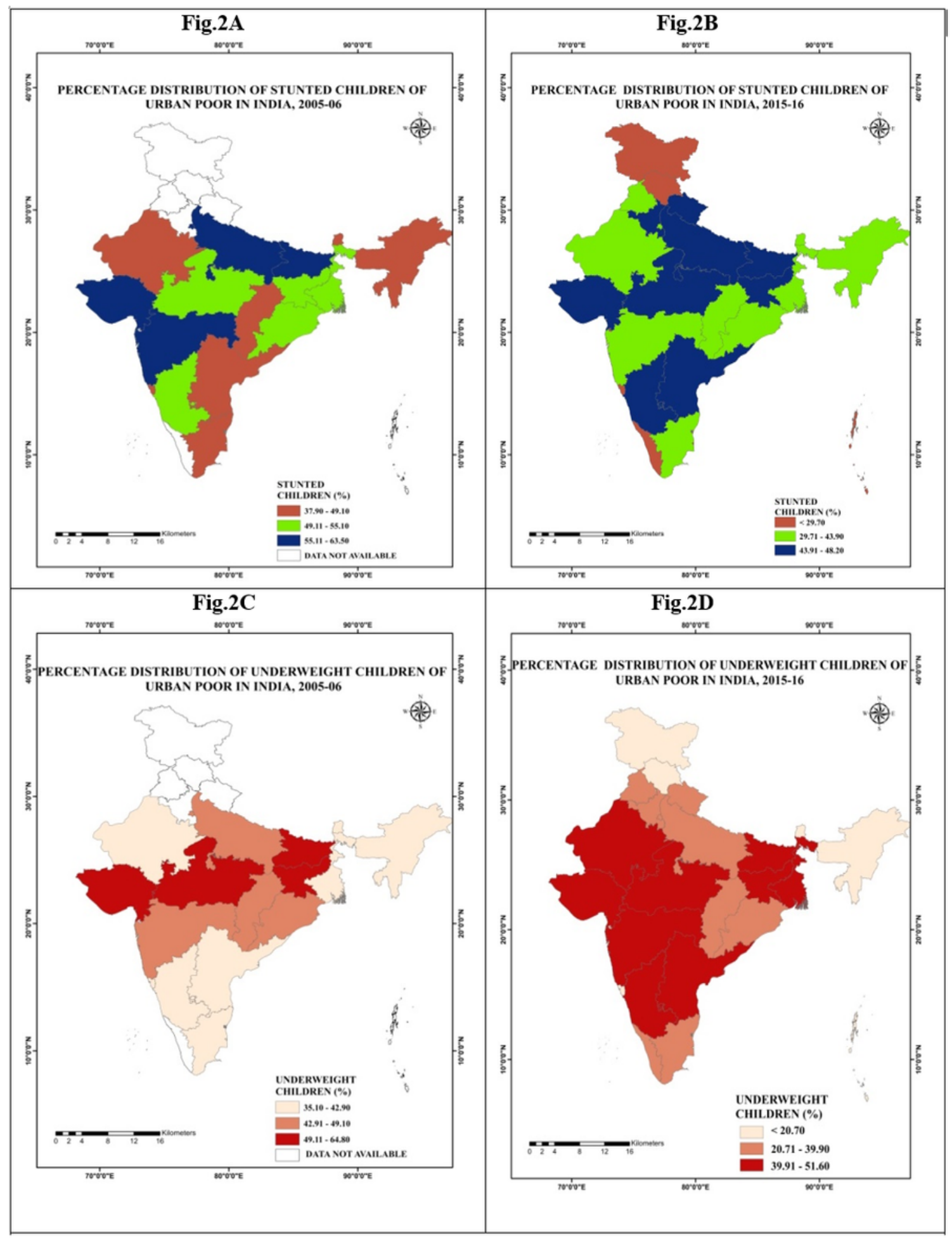

Figure 2

Trends in stunted and underweight children among the urban poor in India, 2005-16. Fig.2A. Percentage distribution of child nutrition of Stunting in 2005-06. Fig.2B. Percentage distribution of child nutrition of Stunting in 2015-16. Fig.2C. Percentage distribution of child nutrition of underweight in 2005-06 and Fig.2D. Percentage distribution of child nutrition of underweight in 2015-16. 


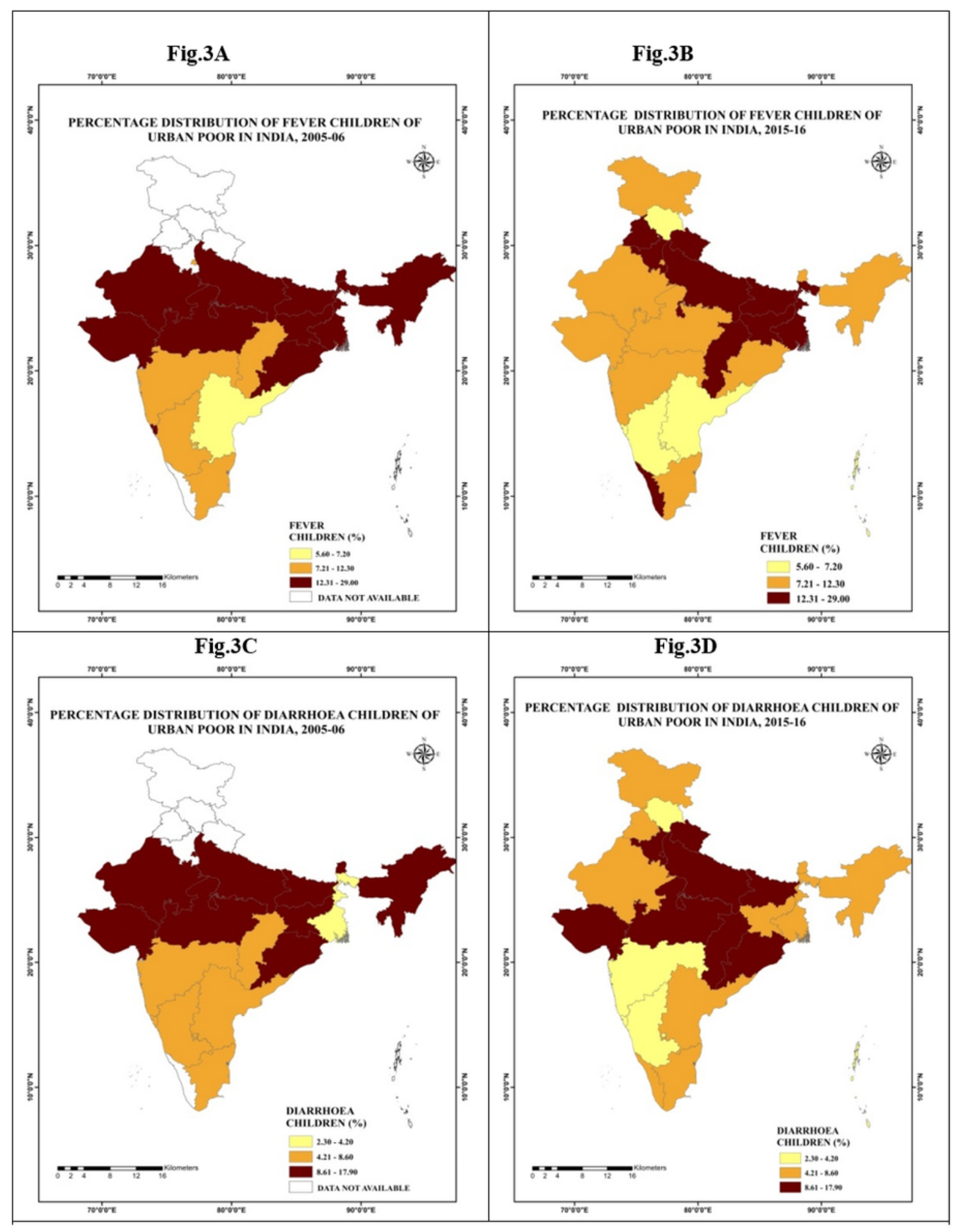

Figure 3

Trends in child illness of fever and diarrhea among the urban poor in India, 2005-16. Fig.3A. Percentage distribution of child illness of Fever in 2005-06. Fig.3B. Percentage distribution of child illness of Fever in 2015-16. Fig.3C. Percentage distribution of child illness of Diarrhoea in 2005-06 and Fig.3D. Percentage distribution of child illness of Diarrhoea in 2015-16. 